\title{
1 Comparison of porous starches obtained from different enzyme types and levels
}

2 Yaiza Benavent-Gil and Cristina M. Rosell*

3 Institute of Agrochemistry and Food Technology (IATA-CSIC), C/ Agustin Escardino,

4 7, Paterna 46980, Valencia, Spain.

5 *Corresponding author e-mail: crosell@iata.csic.es. Phone number +34 963900022. Fax

6 number: +34963636301

7

\section{Abstract}

9 The objective was to compare the action of different hydrolases for producing porous

10 corn starches. Amyloglucosidase (AMG), $\alpha$-amylase (AM), cyclodextrin-

11 glycosyltransferase (CGTase) and branching enzyme (BE) were tested using a range of

12 concentrations. Microstructure, adsorptive capacity, pasting and thermal properties were

13 assessed on the porous starches. SEM micrographs showed porous structures with

14 diverse pore size distribution and pore area depending on the enzyme type and its level;

15 AMG promoted the largest holes. Adsorptive capacity was significantly affected by

16 enzymatic modification being greater influenced by AMG activity. Unexpectedly,

17 amylose content increased in the starch treated with AMG and BE, and the opposite

18 trend was observed in AM and CGTase treated samples, suggesting different mode of

19 action. A heatmap illustrated the diverse pasting properties of the different porous

20 starches, which also showed significant different thermal properties, with lower To and

21 Tp. Porous starch properties could be modulated by using different enzymes and

22 concentrations.

23 Keywords: Porous starch, amyloglucosidase, $\alpha$-amylase, CGTase, branching enzyme,

24 microstructure. 
27 Porous starches are now attracting much attention due to their great adsorption ability

28 (Zhang, Cui, Liu, Gong, Huang \& Han, 2012). Those starches contain abundant pores

29 from the surface to the center of the granules, which increase the specific surface area,

30 acting as excellent natural absorbents. In fact, there is a growing interest in exploiting

31 their properties in different food and non-food areas. In food industry, porous starches are used as colorants, spices, flavorings, sweeteners carriers and also for protection of sensitive elements such as oils, minerals, vitamins, bioactive lipids, food pigments such as $\beta$-carotene and lycopene which are sensitive to light, oxidation or high temperature (Belingheri, Giussani, Rodriguez-Estrada, Ferrillo \& Vittadini, 2015; Luo et al., 2013; Majzoobi, Hedayati \& Farahnaky, 2015).

37 Enzymatic treatments have been performed for obtaining porous starches, mainly applying glucoamylases and $\alpha$-amylases (Sujka \& Jamroz, 2007). Cassava starch granules were treated with $\alpha$-amylase from Bacillus amyloliquefaciens without altering

40 the size or morphology of the granules but significantly changing their properties

41 (Ichihara, Fukuda, Takaha, Yuguchi \& Kitamura, 2013). The combination of

42 glucoamylase and $\alpha$-amylase has been also proposed due to their synergistic action to hydrolyze raw starch completely very rapidly (Sun et al., 2010). In fact, porous starch was obtained using a combination of $\alpha$-amylase and glucoamylases activity after optimizing the kinetic reaction to increase the reaction yield (Zhang, Cui, Liu, Gong,

46 Huang \& Han, 2012). Later, Dura, Błaszczak and Rosell (2014) compared the $\alpha$ amylase and glucoamylase individual action to determine their effect on biochemical features, thermal and structural properties of corn starch. Researchers concluded that $\alpha$ amylase or amyloglucosidase when acting on corn starch at sub-gelatinization temperatures for 24 or 48 hours led to porous starch granules that differed in both, the 
51 microstructure surface and the internal morphology. Similarly, Chen (2012) hydrolyzed

52 native corn starch granules using glucoamylase at $50{ }^{\circ} \mathrm{C}$ for $1-8 \mathrm{~h}$ studying the impact of enzyme/granule ratio and hydrolysis time on the microstructure of porous starch.

Research carried out on enzymatic treatments of starches has been accomplished using diverse enzymes and experimental conditions (Sorndech et al., 2016; Uthumporn, Zaidul \& Karim, 2010), which complicates results comparison and a real understanding of the enzymes action on the structure and functionality of the starches. In addition, other starch acting enzymes like $\alpha$-glucanotransferases have received considerable attention to remodel parts of the amylose and amylopectin molecules by

60 cleaving and reforming $\alpha-1,4$ - and $\alpha-1,6$-glycosidic bond (van der Maarel \& Leemhuis,

61 2013) or in the case of cycloamylose glucanotransferase for producing cyclodextrins

62 (CDs) (Yamamoto, Zhang \& Kobayashi, 2000). Nevertheless, $\alpha$-glucanotransferase such as branching enzyme or the cycloamylose glucanotransferase have been not tested

64 for obtaining porous starches.

The aim of this study was to compare the effect of different enzymes on corn starch

66 properties, taking also into account the impact of enzyme level. Amyloglucosidase

67 (AMG), fungal $\alpha$-amylase (AM), cyclodextrin-glycosyltransferase (CGTase) and branching enzyme (BE) were used to trigger particular starch functionalities.

\section{Materials and methods}

\subsection{Materials}

Corn starch was purchased from Miwon (Seoul, Korea). Amyloglucosidase (EC

3.2.1.3), fungal $\alpha$-amylase (EC 3.2.1.1), cyclodextrin-glycosyltransferase (EC 2.4.1.19) and branching enzyme (EC 2.4.1.18) activities were provided by commercial food grade preparations (Amyloglucosidase 1100, Fungamyl 2500 SG, Toruzyme ${ }^{\circledR} 3.0 \mathrm{~L}$ and 
76 AGU/g (amyloglucosidase activity defined as the amount of enzyme that cleaves 1

$77 \mu \mathrm{mol}$ of maltose per min at $37^{\circ} \mathrm{C}$ ); AM activity was $2500 \mathrm{FAU} / \mathrm{g}$ (fungal amylase activity); CGTase activity was $3 \mathrm{KNU} / \mathrm{mL}$ (kilo novo alpha amylase unit); BE activity was $50000 \mathrm{BEU} / \mathrm{mL}$ (branching enzyme units). All the other chemicals were analytical reagent grade and used without further purification. All solutions and standards were prepared by using deionized water.

\subsection{Preparation of porous starch}

The preparation of porous starch was based on the method of Dura et al. $(2014 ; 2016)$ with minor modifications. Corn starch $(20 \mathrm{~g})$ was suspended in $100 \mathrm{~mL}$ of $20 \mathrm{mM}$ sodium acetate buffer at $\mathrm{pH} 4.0$ (AMG) or sodium phosphate buffer at $\mathrm{pH} 6.0$ (AM, CGTase, BE). Then, different enzyme concentrations, expressed in units of enzyme stock solutions per grams of starch (U/g starch), were added to the starch suspensions, separately. The lowest enzyme concentration was the minimum recommended by the manufacturer (5.5 AMG U/g, 5.5 AM U/g, 0.1 CGTase U/g and 500 BE U/g), increasing concentrations (2, 3, 6 and 10 times the initial level) were also tested. Samples were kept in a shaking water bath $(50 \mathrm{rpm})$ at $50{ }^{\circ} \mathrm{C}$ for $2 \mathrm{~h}$. Then samples were centrifuged for $15 \mathrm{~min}$ at $7000 \times g$ at $4{ }^{\circ} \mathrm{C}$. Supernatants were boiled in a water bath for $10 \mathrm{~min}$ to inactivate the enzymes before any further analyses. Sediments were washed twice with $50 \mathrm{~mL}$ of water, homogenized with a Polytron Ultraturrax homogenizer IKA-T18 (IKA works, Wilmington, USA) for 1 min at speed 3, and then centrifuged at the same conditions as before. Washed sediments were freeze-dried and kept at $4{ }^{\circ} \mathrm{C}$ for subsequent analyses. Starch samples were subjected to the same procedure, without adding enzyme, at $\mathrm{pH} 4.0(\mathrm{~A}-0)$ and $\mathrm{pH} 6.0(\mathrm{P}-0)$, and used as references. Two batches were prepared for each treatment.

\subsection{Scanning electron microscopy (SEM)}


101 The granule morphology of native, controls and treated starches was observed using a

102 JSM 5200 scanning electron microscope (SEM) (JEOL, Tokyo, Japan). Samples were

103 coated with gold in a vacuum evaporator (JEE 400, JEOL, Tokyo, Japan) prior to

104 observation. The obtained samples were examined at an accelerating voltage of $10 \mathrm{kV}$

105 and magnified 3,500x times.

106 The microstructure analysis was carried out using the image analysis program (ImageJ,

107 UTHSCSA Image Tool software). The SEM images were saved as 8-bit tiff format.

108 Scale was initially set using the relationship between pixels and known distance.

109 Threshold was assessed applying the default algorithm and then particle analysis was

110 carried out. The following parameters were measured: granule size and the pore size.

111 The area occupied by pores in a starch granule was calculated as the sum of the areas of

112 all the pores of a starch granule divided by granule pore. Values were the average of 20

113 independent measurements.

114 2.4. High performance anion exchange chromatography (HPAEC)

115 The hydrolysis compounds (oligosaccharides and CDs) lixiviated during enzymatic

116 treatment were quantified according to Dura and Rosell (2016). Samples were filtered

117 through a $0.45 \mu \mathrm{m}$ pore size membrane (Millex-HV) and then injected (10 $\mu \mathrm{L})$ into

118 HPAEC through a CarboPac PA-100 column $(250 \mathrm{~mm} \times 4 \mathrm{~mm})$ at flow rate 1.0

$119 \mathrm{~mL} / \mathrm{min}$, coupled to a pulsed amperometric detector (Dionex). Solutions included: A

120 (water), $\mathrm{B}(1 \mathrm{~mol} / \mathrm{L} \mathrm{NaOH})$ and $\mathrm{C}(1 \mathrm{~mol} / \mathrm{L} \mathrm{C} 2 \mathrm{H} 3 \mathrm{NaO} 2)$. Running profile applied was:

121 time zero, $92.5 \% \mathrm{~A}, 5 \% \mathrm{~B}, 2.5 \% \mathrm{C} ; 25 \mathrm{~min}, 85 \% \mathrm{~A}, 5 \% \mathrm{~B}, 10 \% \mathrm{C} ; 1 \mathrm{~min}, 70 \% \mathrm{~A}, 15 \%$

$122 \mathrm{~B}, 15 \% \mathrm{C} ; 3 \mathrm{~min}, 66 \% \mathrm{~A}, 15 \% \mathrm{~B}, 19 \% \mathrm{C} ; 5 \mathrm{~min}, 57 \%$ A, $15 \% \mathrm{~B}, 28 \% \mathrm{C} ; 1.5 \mathrm{~min}, 37 \%$

123 A, $15 \%$ B, 48\% C. Standards of known concentrations were previously analyzed.

124 2.5. Amylose content of enzymatically treated starches 
125 The amount of amylose of the starches was analyzed in triplicate using a commercial

126 assay kit (Megazyme International Ireland Ltd., Bray, Co. Wicklow, Ireland) based on

127 the concanavalin A method (Gibson, Solah \& McCleary, 1997).

\section{2.6. Damage starch}

129 Damaged starch levels were estimated at least in duplicate following the American

130 Association of Cereal Chemists, method 76-31.01 (2000).

$131 \quad$ 2.7. Adsorption of water and sunflower oil

132 Adsorptive capacity of starches for water and sunflower oil were determined according

133 to the method described by Yousif, Gadallah and Sorour (2012) with a slight

134 modification. Starch $(0.1 \mathrm{~g})$ and solvent $(1 \mathrm{~mL}$, water or oil) were mixed and vortexed

135 for $30 \mathrm{~min}$ at room temperature. Slurries were centrifuged 10 minutes at 3,000 $\mathrm{x} g$ and

136 decanted. When no more water or sunflower oil was dropped off onto the filter paper,

137 weight of the sediment was measured. The adsorption capacity was calculated as the

138 weight of the wetted sediment divided by the dry weight of sample $(\mathrm{g} / \mathrm{g})$.

139 2.8. Viscosity measurement

140 The pasting properties of native and enzymatically modified starches were measured

141 with the Rapid Visco Analyzer (RVA-4500, Perten Instruments, Hägersten, Sweden).

142 Starch ( $2 \mathrm{~g}$ based on $14 \%$ moisture content) was added to $20 \mathrm{~mL}$ of water placed into

143 the aluminum RVA canister. Slurries underwent a controlled heating and cooling cycle,

144 from 50 to $95^{\circ} \mathrm{C}$ in $282 \mathrm{~s}$, holding at $95^{\circ} \mathrm{C}$ for $150 \mathrm{~s}$ and then cooling to $50{ }^{\circ} \mathrm{C}$. The

145 initial speed for mixing was $960 \mathrm{rpm}$ for $10 \mathrm{~s}$, followed by a $160 \mathrm{rpm}$ paddle speed that

146 was maintained for the rest of assay. Pasting parameters such as pasting temperature,

147 peak viscosity, breakdown (peak viscosity-hot paste viscosity), final viscosity, setback

148 (cold paste viscosity-peak viscosity) were recorded using Thermocline software for

149 Windows (Perten Instruments, Hägersten, Sweden). 
151 The gelatinization characteristics of modified starches were determined using a

152 differential scanning calorimetry (DSC) from Perkin-Elmer (DSC 7, Perkin-Elmer

153 Instruments, Norwalk,CT). The slurry of starch and water (3:1) was placed into stainless

154 steel capsules. Capsules were hermetically sealed and equilibrated at room temperature

155 for one hour before analysis. The samples were scanned from 30 to $120^{\circ} \mathrm{C}$ at a heating

156 rate of $10^{\circ} \mathrm{C} / \mathrm{min}$ under nitrogen atmosphere, using an empty stainless steel capsule as

157 reference. The temperature values obtained were the onset temperature (To), peak

158 temperature (Tp), and conclusion temperature (Tc). The enthalpy of gelatinization $(\Delta \mathrm{H})$

159 was estimated based on the area of the main endothermic peak, expressed as joule per

160 gram sample $(\mathrm{J} / \mathrm{g})$.

$161 \quad 2.10 . \quad$ Statistical analysis

162 All experiments were repeated at least in duplicate. Experimental data were statistically

163 analyzed using an analysis of variance (ANOVA) and values were expressed as a mean

$164 \pm$ standard deviation. Fisher's least significant differences test was used for assessment

165 of significant differences among experimental mean values with $95 \%$ confidence.

166 Statistical computations and analyses were conducted using Statgraphics Centurion XV

167 software (Bitstream, Cambridge, N).

\section{3. Results}

\section{3.1. Microstructure analysis}

170 The shape, size, structure and surface characteristics of corn starch granules tested

171 (native, references and treated starches) were investigated using SEM (Figure 1). Native

172 starch granules displayed an irregular and mostly polygonal shape with relatively

173 smooth surface (Figure 1a). Reference starches (Figure 1 b,c) had similar appearance to

174 native starch, showing no evidence of rupture, breakage or pores due to the incubation 
179 with buffer; results that were analogous to those reported previously (Dura, Błaszczak

180 \& Rosell, 2014; Dura \& Rosell, 2016). The effect of enzymatic treatment was readily

181 visible in the modified starches microstructure, obtaining in all cases porous starch

182 granules, without affecting the shape of the granule (Figure $1 \mathrm{~d}-\mathrm{w}$ ).
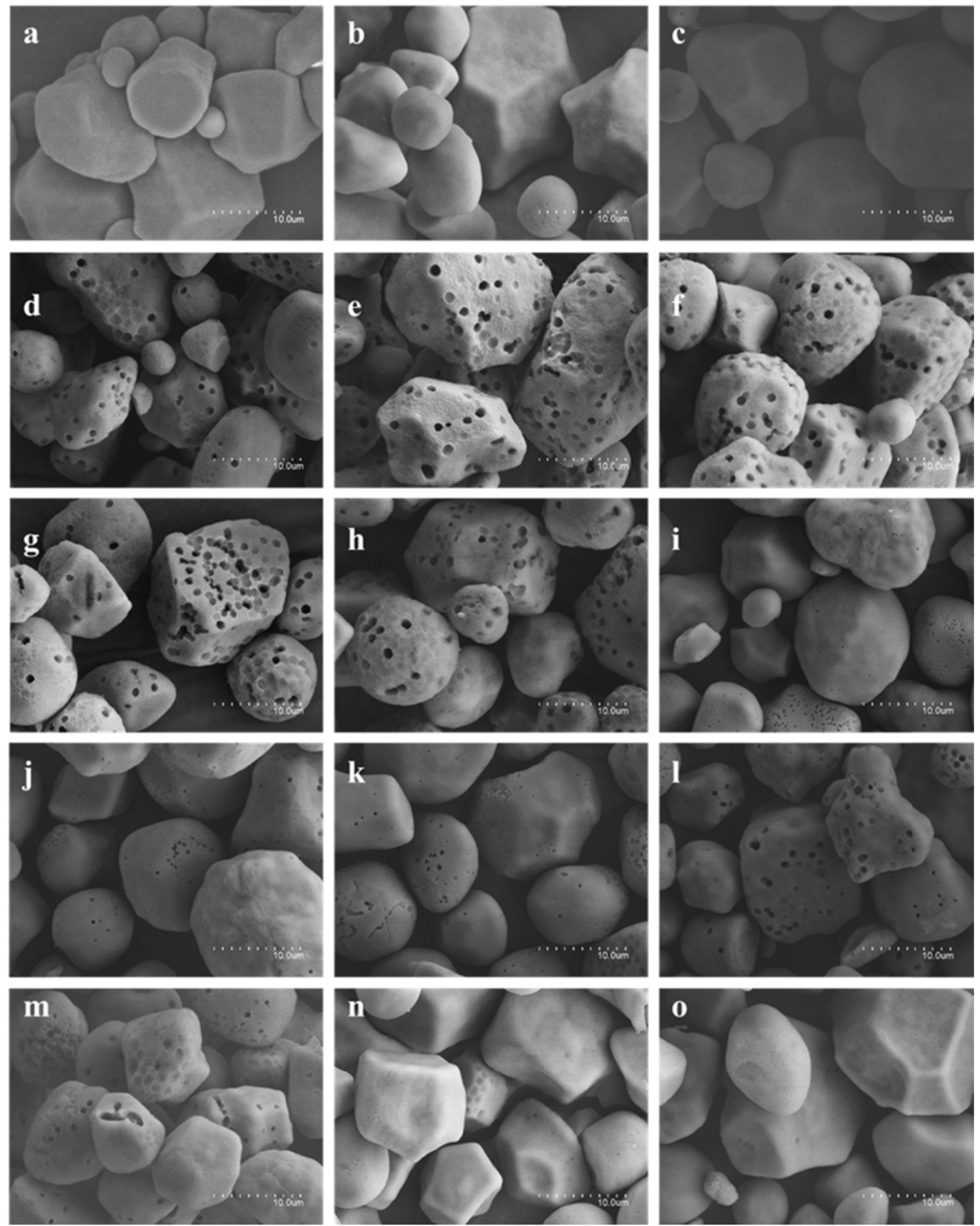

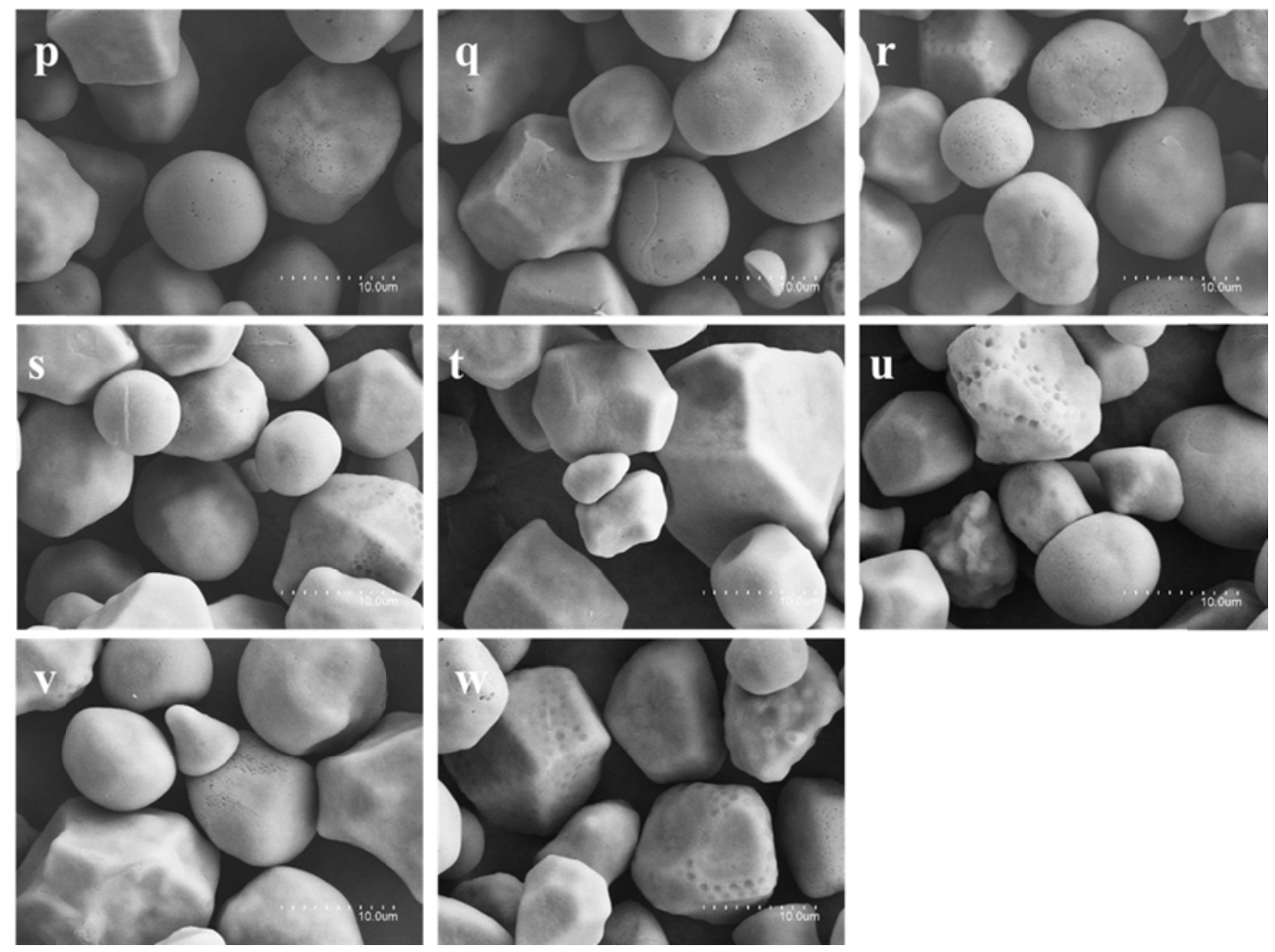

186 Figure 1: Scanning electron micrograph of and native corn starch (a), samples treated

187 enzymatically (d-w) and their counterparts controls (b and c). Magnification 3500×. Reference

188 A-0 (b); Reference P-0 (c); AMG 5.5, 11, 16.5, 33 and 55 (d-h); AM 5.5, 11, 16.5, 33 and 55 (i-

$189 \mathrm{~m}$ ); CGTase 0.1, 0.2, 0.3, 0.6 and 1 (n-r); BE 500, 1000, 1500, 3000 and 5000 (s-w). Numbers

190 following enzyme abbreviations are referred to the enzyme activity applied.

197 To give some objective results about the action of the enzymes, the pore size and the

198 ratio pore area to starch granule area (related to the abundance of pore per granule) were

199 quantified using image analysis (Figure 2). The pore size as well as pore area

100 distribution was significantly affected by the type of enzyme and also their level. AMG

101 action resulted in starch granules with larger pores and wider size distribution (Figure 2

102 A). In opposition, CGTase led to the lowest pore size. As the concentration of AMG

103 increased, the size of the pores progressively augmented until 16.5 U of AMG were

104 added; at higher enzyme level no further pore size increase was observed, although a

105 significant increase in the ratio pore area to granule area was observed (Figure 2 B)

106 indicating more pores per granule. Nevertheless, it was noted that at higher AMG

1:07 concentrations appeared some depressions in the granules, which resulted from the 
197 eroding action of the enzyme onto the granule surface. Aggarwal and Dollimore (2000)

198 also observed a visible increase in the size of the pores when augmented the AMG

199 concentrations, till enzyme activity ( $800 \mathrm{U} / \mathrm{g}$ starch) was so pronounced that walls

200 around pinholes were broken, leading to large irregular holes and broken structure.

201 Similarly, pore size increased with the amount of AM or CGTase added, although both

202 treatments resulted in smaller pore size than AMG treatment. The ratio pore to granule

203 area of AM treated starches also maintained a similar pattern to the AMG samples,

204 while it remained constant when CGTase enzyme was used. The BE enzyme produced

205 very irregular pore sizes without any trend with the level of enzyme. It should be noted

206 that the pore size was bigger when lower concentrations of enzymes were used, but in

207 those cases pores resembled wide craters instead of deep holes. At higher enzyme

208 concentration, smaller and deeper pinholes appeared, leading a mixture of

209 heterogeneous sizes.

210 When starch granules are incubated with amylolytic enzymes, the enzymes migrate

211 through the channels and initiate hydrolysis leading to an inside out pattern of digestion

212 (Chen \& Zhang, 2012). Nevertheless, the present study reveals that different porous

213 starches could be obtained depending on the type, thus it is possible to modulate the

214 number and size of pores by using either different amylolytic enzyme or level of

215 enzyme. 

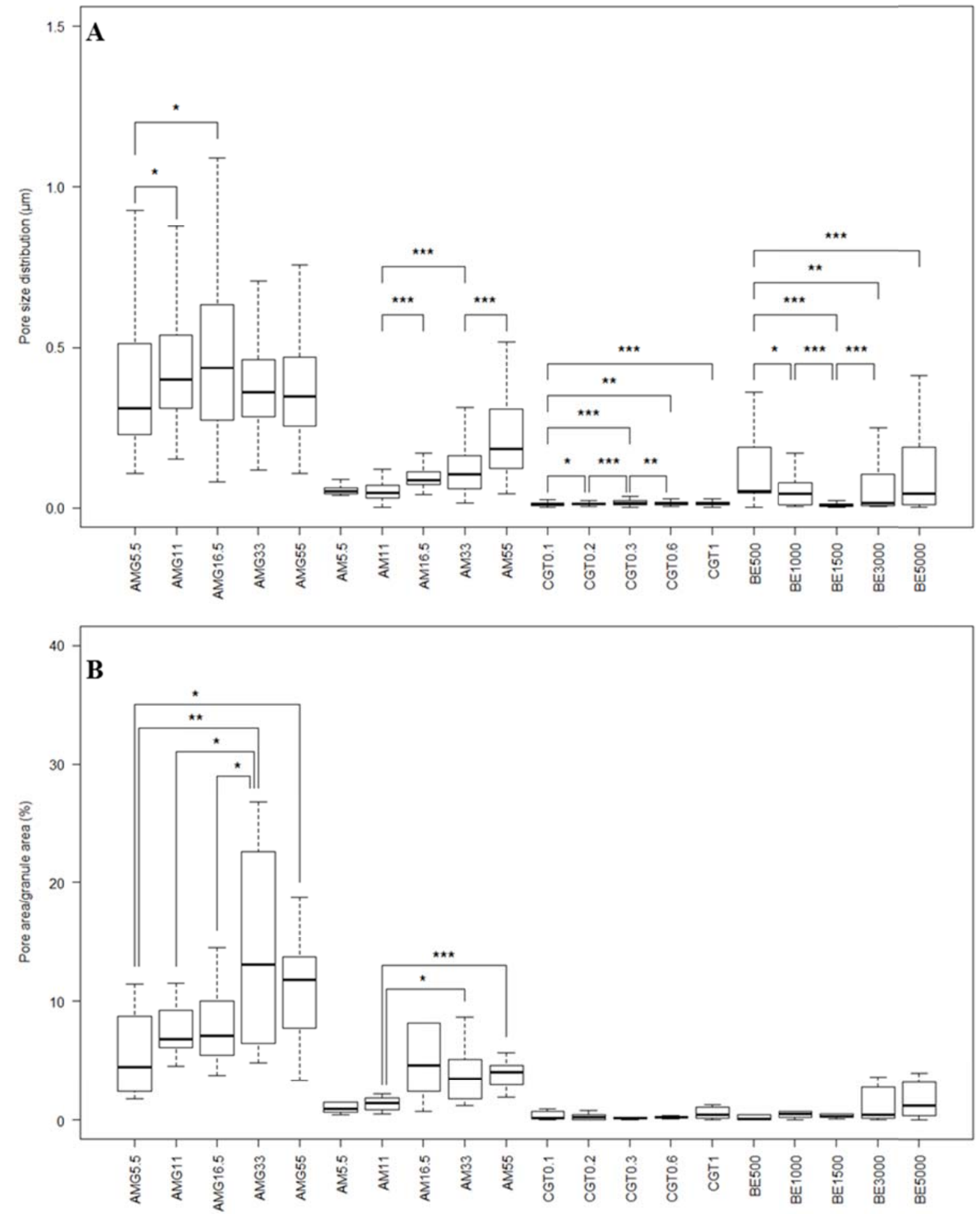

Figure 2: Image analysis from SEM photographs. A) Pore size and B) pore surface area distribution for each enzyme by boxplot. Numbers following enzyme abbreviations are referred to the enzyme activity applied.

\subsection{CDs and oligosaccharides released during enzymatic treatment}


221 To understand the action of the enzymes on the starch granules, the released compounds

222 after the incubation were analyzed. Table 1 listed the oligosaccharides and cyclodextrins

223 contents released per starch $\left(\mathrm{mg} 100 \mathrm{~g}^{-1}\right)$. As expected, neither oligosaccharides nor

224 cyclodextrins (CDs) were released from the reference samples (data not shown), neither

225 from AMG treatment. No oligosaccharides (from DP1 to DP5) were released when corn

226 starches were subjected to BE hydrolysis. BE cleaves $\alpha-(1 \rightarrow 4)$-O-glycosidic bonds

227 and transfers the cleaved-glucan to $\alpha-(1 \rightarrow 6)$ position leading to branched glucan

228 mixtures (Roussel et al., 2013).

229 
230 Table 1: Oligosaccharides and cyclodextrins released after corn starch hydrolysis by AMG, AM and CGTase. Results are expressed in mg $100 \mathrm{~g}^{-1}$ of starch.

\begin{tabular}{|c|c|c|c|c|c|c|c|c|}
\hline $\begin{array}{c}\text { Enzyme } \\
\text { type }\end{array}$ & $\begin{array}{c}\text { Enzyme } \\
\text { (U/g starch) }\end{array}$ & Glucose & Maltose & Maltotetriose & Maltotetraose & Maltopentaose & $\alpha-C D$ & $\beta-C D$ \\
\hline \multirow[t]{5}{*}{ AMG } & 5.5 & $16.19 \pm 1.31$ & n.d & n.d & n.d & n.d & n.d & n.d \\
\hline & 11 & $15.64 \pm 1.39$ & n.d & n.d & n.d & n.d & n.d & n.d \\
\hline & 16.5 & $16.16 \pm 1.17$ & n.d & n.d & n.d & n.d & n.d & n.d \\
\hline & 33 & $15.57 \pm 1.08$ & n.d & n.d & n.d & n.d & n.d & n.d \\
\hline & 55 & $15.49 \pm 1.01$ & n.d & n.d & n.d & n.d & n.d & n.d \\
\hline \multirow[t]{5}{*}{$\mathbf{A M}$} & 5.5 & $9.76 \pm 0.04$ & $10.81 \pm 0.20$ & $7.68 \pm 0.13$ & $2.05 \pm 0.02$ & n.d & n.d & n.d \\
\hline & 11 & $11.60 \pm 0.27$ & $8.82 \pm 0.22$ & $3.23 \pm 0.40$ & $1.90 \pm 0.14$ & $0.18 \pm 0.00$ & n.d & n.d \\
\hline & 16.5 & $12.42 \pm 0.06$ & $9.48 \pm 0.39$ & $2.38 \pm 0.17$ & $1.57 \pm 0.38$ & n.d & n.d & n.d \\
\hline & 33 & $13.94 \pm 0.41$ & $9.70 \pm 0.13$ & $0.55 \pm 0.05$ & $1.18 \pm 0.01$ & n.d & n.d & n.d \\
\hline & 55 & $15.23 \pm 0.16$ & $10.49 \pm 0.20$ & $0.27 \pm 0.09$ & $0.42 \pm 0.08$ & n.d & n.d & n.d \\
\hline \multirow[t]{5}{*}{ CGTase } & 0.1 & $1.23 \pm 0.03$ & $0.54 \pm 0.05$ & $0.51 \pm 0.09$ & $0.50 \pm 0.13$ & $0.01 \pm 0.00$ & $2.25 \pm 0.09$ & n.d \\
\hline & 0.2 & $1.37 \pm 0.03$ & $1.07 \pm 0.00$ & $0.85 \pm 0.04$ & $0.96 \pm 0.06$ & $0.02 \pm 0.00$ & $2.33 \pm 0.06$ & n.d \\
\hline & 0.3 & $0.83 \pm 0.04$ & $1.07 \pm 0.05$ & $0.93 \pm 0.04$ & $1.22 \pm 0.09$ & $0.02 \pm 0.00$ & $2.73 \pm 0.24$ & n.d \\
\hline & 0.6 & $0.70 \pm 0.08$ & $1.19 \pm 0.17$ & $0.97 \pm 0.13$ & $1.00 \pm 0.13$ & $0.01 \pm 0.00$ & $1.73 \pm 0.02$ & n.d \\
\hline & 1 & $1.27 \pm 0.02$ & $1.78 \pm 0.00$ & $1.37 \pm 0.02$ & $1.60 \pm 0.05$ & $0.03 \pm 0.00$ & $2.09 \pm 0.14$ & n.d \\
\hline
\end{tabular}


233 Regarding the other amylolytic enzymes, starch-converting enzymes have been

234 classified into exo-amylases and endo-amylases owing to their cleavage action, and

235 results displayed that difference (Table 1). AMG treatment released exclusively glucose,

236 and the amount remained constant independently on the enzyme concentration.

237 Amyloglucosidase is a well-known exo-amylase, releasing only glucose residues from

238 amylose or amylopectin chains (Bouchet-Spinelli, Coche-Guérente, Armand, Lenouvel,

239 Labbé \& Fort, 2013). However, saturation of the non-reducing-ends of starch chains has

240 been reported when enough glucoamylase is present (Chen \& Zhang, 2012), which

241 would explain the steady glucose level.

242 In addition, the endo-amylases, AM and CGTase, are able to cleave $\alpha-1-4$ glycosidic

243 bonds existing in the internal part (endo-) of a polysaccharide chain. As expected, AM

244 majorly converted starch to glucose followed by maltose. Moreover, the amount of

245 short chain oligosaccharides, ranging from DP1 to DP2 increased with the amount of

246 AM added, whereas DP3, DP4 and $\alpha$-CD chains decreased. Conversely, the amount of

247 short chain oligosaccharides ranging from DP1 to DP5 decreased as increasing the level

248 of CGTase added, with a simultaneous increase in $\alpha$-CD. Overall, CGTases convert

249 amylose or amylopectin into a mixture of $\alpha$-, $\beta$ - and $\gamma$-CD and some dextrins, and the

250 proportion was dependent on the enzyme specificity (Terada, Yanase, Takata, Takaha \&

251 Okada, 1997), but also on the substrate, complexing agents and reaction conditions

252 (Blackwood \& Bucke, 2000).

253 3.3. Amylose, damaged starch content and adsorptive capacity

254 Amylose and damaged starch contents were determined in the treated starches (Table

255 2). The statistical analysis indicated that the enzymatic treatment significantly modified

256 the amylose content, the amount of damage starch and the adsorption properties of the

257 starches; but the enzyme level only prompted significant effect on the amount of 
damage starch and adsorptive water capacity. Amylose content showed a significant moderate correlation with the damaged starch content ( $r=0.6684, P<0.0000)$, mainly ascribed to the action of AMG and BE. Concerning the specific action of each enzyme, a significant reduction in amylose content, with the subsequent increase in amylopectin, was observed after AM and CGTase treatments, without observing any trend with the

263 level of enzyme applied. These results are in agreement with the inverse relationship 264 reported between the amylose content and the amount of hydrolyzed starch (Tester, Qi \& Karkalas, 2006), and also with the trend reported for CGTase modified starches (Dura \& Rosell, 2016),. Nevertheless, previous results with AM and AMG indicated that at lower concentrations than the one of the present study no change in the amylose content was observed even when increasing the enzymatic treatment to 24 or 48 hours

269 (Dura, Błaszczak \& Rosell, 2014).

270 Damaged starch was hardly affected by the action of AM and CGTase, although a

271 tendency to decrease it was observed in the case of CGTase. Considering that

272 microstructure analysis confirmed the impairment of the granule, it seems that the

273 experimental assay for quantifying damage starch was not sensible or reliable enough to

274 distinguish the degree of damage. Conversely, AMG and BE treatment promoted the opposite trend, the amylose content appeared to increase but not always significantly, and the amount of damage starch significantly augmented, particularly in the case of

277 BE. Regarding the level of BE applied, a clear decrease of damage starch content was

278 observed when increasing the enzyme concentration. Starch granules have a unique

279 semi-crystalline supramolecular structure with concentric layers of amorphous and 280 crystalline regions radiating from the hilum (Ratnayake \& Jackson, 2008). Taking into 281 account that the amylopectin side chains form the framework of the crystalline lamellae, 282 with branching points located in the amorphous domains, where the majority of the 
283 amylose is located (Copeland, Blazek, Salman \& Tang, 2009), it seems that depending

284 on the enzymatic treatment amylose or amylopectin are preferentially hydrolyzed.

285 Results on amylose content suggested that AM and CGTase attacked more proportion

286 of amylose, leading an increase in the amount of amylopectin, suggesting deeper

287 pinholes and the attack of amorphous and crystalline structure. In opposition, AMG and

288 BE seem to hydrolyze preferentially the amylopectin chains, increasing the proportion

289 of amylose in the surface of starch granule, thus bigger and less deep holes, which

290 agrees with microstructure results. 


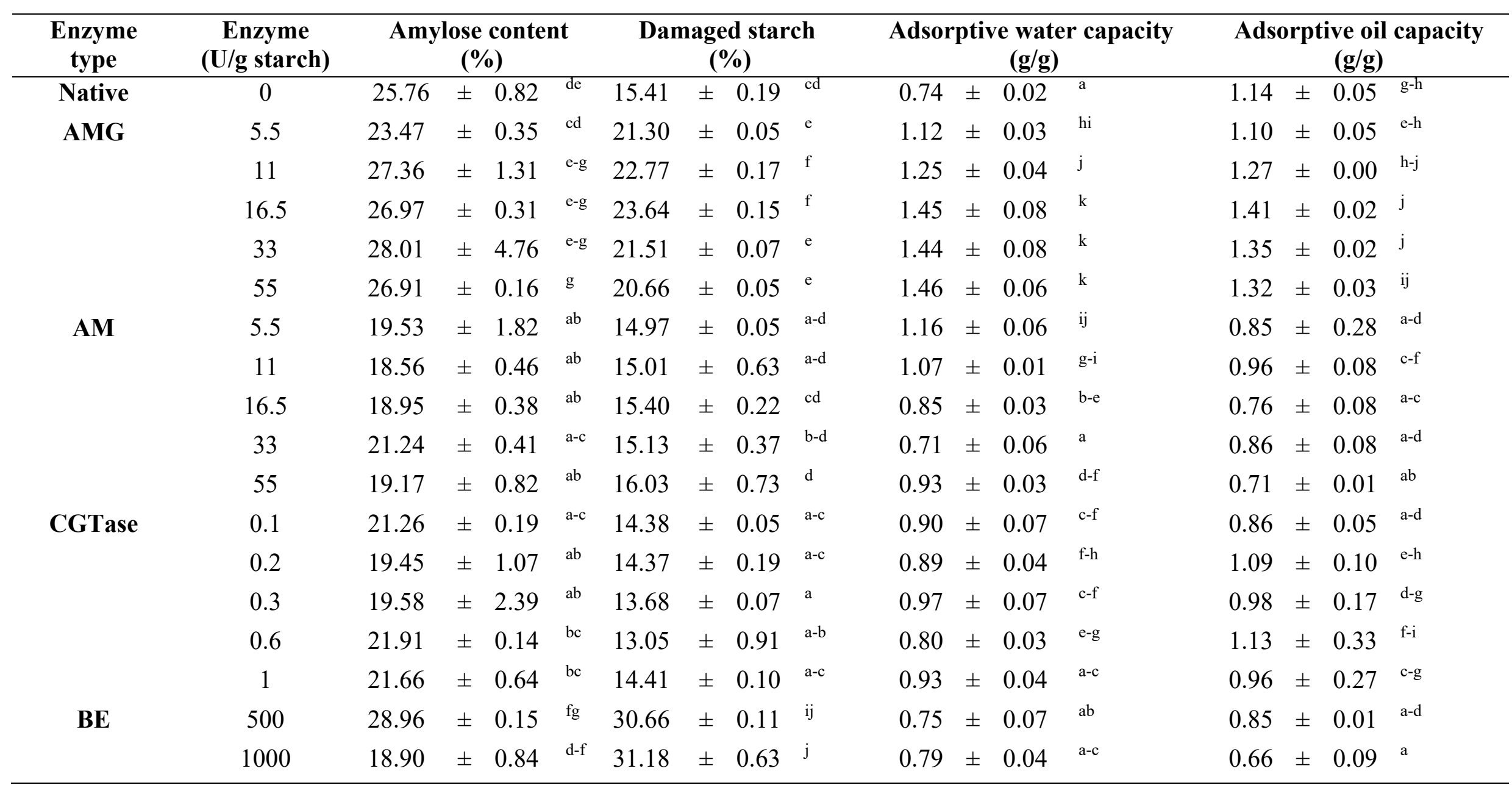




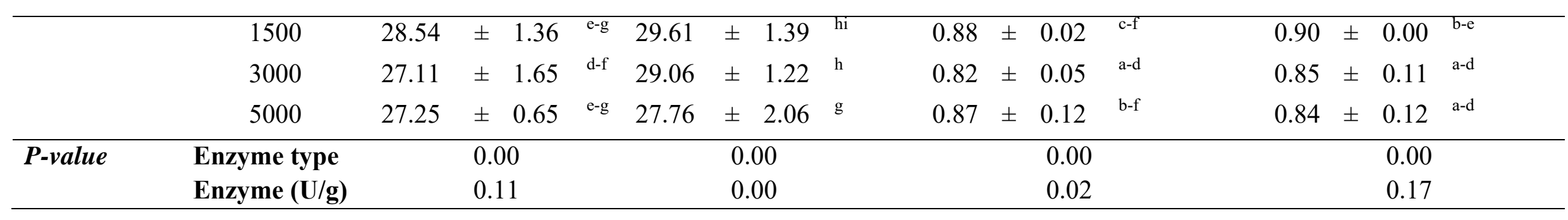


294 The adsorptive capacity of modified starches for water and sunflower oil are also

295 summarized in Table 2. The hydrophilic nature was significantly dependent on both

296 enzyme type and concentration, while hydrophobic nature depended only on the enzyme

297 type. In general, all enzymatic treatments increased the water adsorption capacity of the 298 starches; among them, AMG showed the greatest effect, followed by AM, CGTase and

299 BE treatment. Likely, the size of the pores originated by AMG was responsible of this

300 behavior due to the increase of the surface area. The adsorptive oil capacity of starch

301 was only significantly modified when treated with AMG. Chen and Zhang (2012)

302 obtained an increase in both solvents retention ability respect to native starch, due to the

303 increase in the surface area promoted by the starch treatment with AMG (11 U/g

304 starch), which agrees with results of the present study. Therefore, it seems that the pore

305 size plays a fundamental role for oil adsorption, which was only sufficient in the case of

306 AMG hydrolysis.

307 3.4. Enzymatic modification effects on pasting and thermal starch properties

308 To illustrate the pasting characteristics of the porous starches obtained from different

309 type of enzymes a heatmap was constructed with the pasting properties (Figure 3 ). The

310 heatmap of the hierarchical clustering of the RVA properties for the modified samples

311 was analyzed on the basis of similarities and differences in starch pasting properties,

312 including onset, peak viscosity, through, breakdown, final viscosity, setback, hydrolysis

313 percentage at $95{ }^{\circ} \mathrm{C}$ and $50{ }^{\circ} \mathrm{C}$ (Figure 3). The dendrogram consisted of three major

314 clusters. One cluster contained native, AM treated samples and the minor concentration

315 of CGTase and BE treatments, up to $1500 \mathrm{U} / \mathrm{g}$ starch. Another cluster essentially

316 included AMG treated starches and one AM treated sample. The last cluster comprised

317 CGTase and BE treated starches using high enzyme levels. 
Color Key
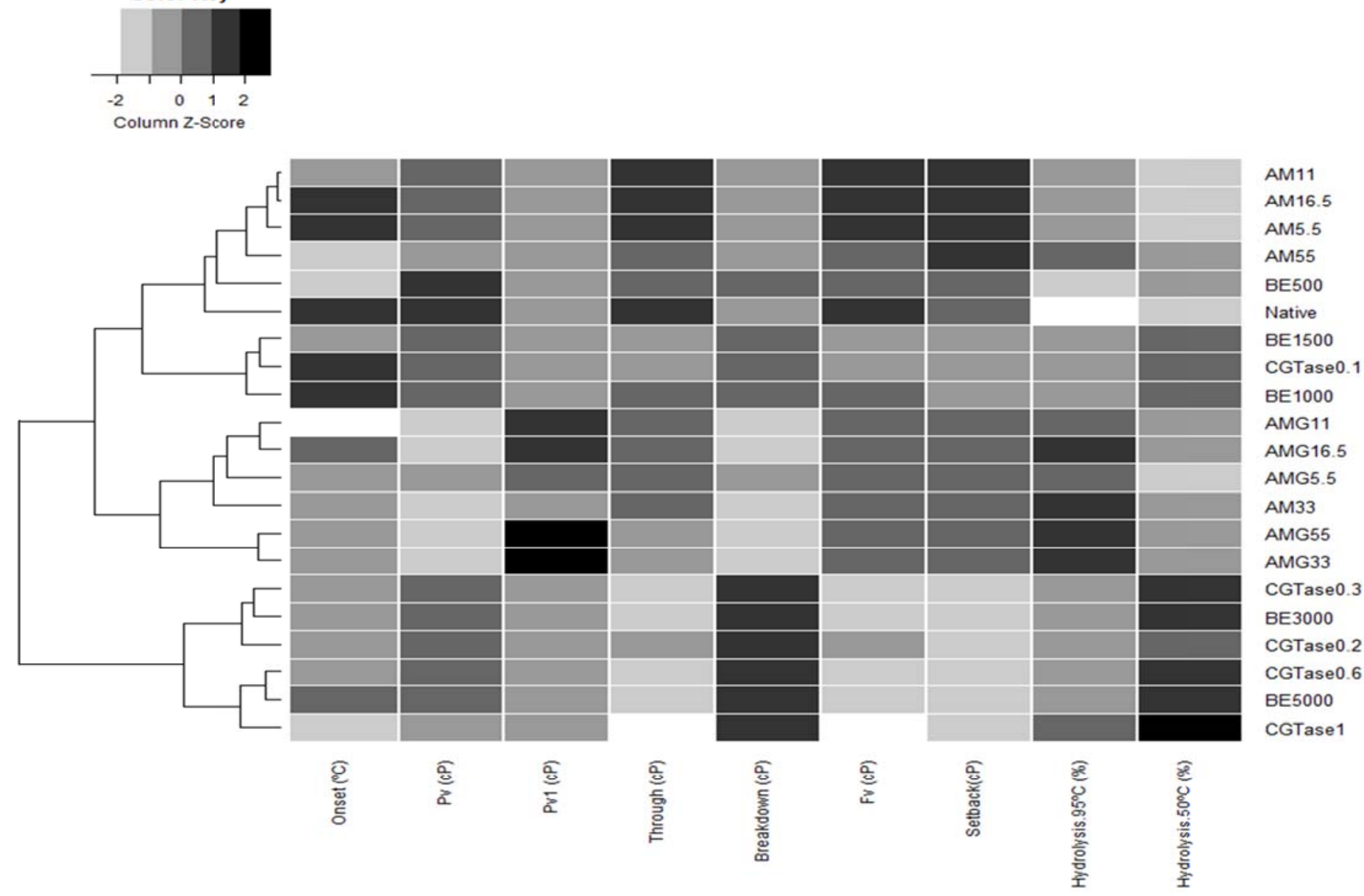

Figure 3: Hierarchical clustering of RVA profiles. A heat map representing the hierarchical clustering of the $Z$ scores of the enzyme activities related to viscoelastic properties, when compared AMG, AM, CGTase and BE enzyme treatment. The Z scores represent the dispersion around the overall mean of the viscoelastic properties and weighted by their standard errors. The scale of the intensity is shown in the top corner. Rows represent samples and column viscoelastic properties. Numbers following enzyme abbreviations are referred to the enzyme activity applied. Pv: peak viscosity; Pv1: additional peak viscosity; Fv: final viscosity 
323 It was evident from the heatmap that enzymes changed the pasting performance of

324 starch suspensions and the effect was also dependent on their concentrations,

325 particularly in the case of CGTase and BE. The onset temperature, indicative of the

326 initial viscosity increase, was significantly decreased by all enzyme studied,

327 independently of the concentration used. Therefore, lower cooking temperature was

328 required for the gelatinization of porous starches, likely due to faster water absorption

329 on the starch granules, since a negative correlation was observed between onset

330 temperature and pore size $(r=-0.4581, P<0.001)$. AM treated samples showed similar

331 pasting behavior to native starch, unless the maximum viscosity that decreased after

332 treatment. AM acts on the starch molecules breaking $\alpha-(1-4)$ linkages and providing

333 dextrins, which present lower swelling during gelatinization (Rocha, Carneiro \&

334 Franco, 2010). Porous starches had significantly lower peak viscosity, through, final

335 viscosity and setback compared to native, which agree with previous results (Dura,

336 Błaszczak \& Rosell, 2014). In the case of AMG treated samples they were grouped due

337 to their lower peak viscosity and breakdown and higher final viscosity and setback,

338 besides the presence of an additional peak viscosity (Pv1) during heating, prior to the

339 common peak viscosity at $95^{\circ} \mathrm{C}$. This additional peak was negatively correlated with

340 peak viscosity, showing a progressive increase in the first peak in parallel to the

341 reduction of peak viscosity. The decrease of peak viscosity due to the joint action of $\alpha-$

342 amylase and glucoamylase has been explained by the disintegration of fragile granules

343 owing to their porous structure, leading to less viscous slurries (Uthumporn, Zaidul \&

344 Karim, 2010). In this regard, pore size, ratio of pore area to granule area and water

345 adsorptive capacity was negatively correlated with peak viscosity, confirming this

346 hypothesis. 
347 Porous starches obtained with very high levels of CGTase or BE were mainly

348 characterized by very low values of final viscosity and setback, and high breakdown

349 values. Those effects have been reported when wheat starch was treated by CGTase

350 Gujral and Rosell (2004).

351 The values for the thermal properties of native starch (Table 3) agrees with previous

352 reported results for corn (Jane et al., 1999). In modified starches, To, Tp and $\Delta H$

353 significantly $(P<0.05)$ varied owing to the type of enzyme used and its level, but Tc

354 was only significantly affected by the type of enzyme. Porous starches showed lower To

355 and Tc than native starch. In the case of AMG treated starches those temperatures

356 decreased when increasing the level of enzyme during treatment. Moreover, lower

357 energy $(\Delta \mathrm{H})$ was required to promote starch gelatinization, likely due to less energy was

358 needed to unravel and melt the unstable double helices during gelatinization (Chung,

359 Liu \& Hoover, 2009).

360 On the other hand, BE enzyme produced starches with lower To and Tp, but similar Tc

361 to native starch. Conclusion temperature (Tc) was only significantly reduced by AM.

362 Correlation analysis indicated that all gelatinization parameters evaluated except

363 enthalpy were positively correlated $(P<0.05)$ with amylose content, but not with

364 damaged starch, pore size or pore area to starch granule, which are in agreement with

365 previous observations (Stevenson, Doorenbos, Jane \& Inglett, 2006). In addition,

366 enthalpy was negatively correlated with water $(r=-0.3555, P<0.05)$ and oil adsorption

367 capacity $(r=-0.4078, P<0.01)$. 
Table 3: Thermal properties of enzymatically modified corn starches determined by DSC

\begin{tabular}{|c|c|c|c|c|c|c|c|c|c|c|c|c|c|c|c|c|c|}
\hline \multirow{2}{*}{$\begin{array}{c}\text { Enzyme } \\
\text { type } \\
\text { Native }\end{array}$} & \multirow{2}{*}{$\begin{array}{c}\text { Enzyme } \\
\text { (U/g starch) } \\
0\end{array}$} & \multicolumn{4}{|c|}{$\mathrm{T}_{0}\left({ }^{\circ} \mathrm{C}\right)$} & \multicolumn{4}{|c|}{$T_{p}\left({ }^{0} \mathrm{C}\right)$} & \multicolumn{4}{|c|}{$\mathbf{T}_{\mathrm{c}}\left({ }^{\circ} \mathrm{C}\right)$} & \multicolumn{4}{|c|}{$\Delta \mathbf{H}(\mathbf{J} / \mathbf{g})$} \\
\hline & & 63.28 & \pm & 0.14 & $\mathrm{i}$ & 68.20 & \pm & 0.00 & $\mathrm{~h}$ & 74.71 & \pm & 0.17 & $\mathrm{~b}$ & 20.66 & \pm & 1.27 & c-e \\
\hline \multirow[t]{5}{*}{$\mathrm{AMG}$} & 5.5 & 62.96 & \pm & 0.21 & $g-i$ & 66.70 & \pm & 0.24 & $\mathrm{a}-\mathrm{e}$ & 74.32 & \pm & 0.68 & $\mathrm{~b}$ & 20.26 & \pm & 1.08 & b-e \\
\hline & 11 & 63.26 & \pm & 0.10 & hi & 67.53 & \pm & 0.00 & $\mathrm{~g}$ & 74.86 & \pm & 0.08 & $\mathrm{~b}$ & 19.18 & \pm & 1.70 & bc \\
\hline & 16.5 & 63.26 & \pm & 0.15 & hi & 67.37 & \pm & 0.47 & $\mathrm{fg}$ & 74.65 & \pm & 0.11 & $\mathrm{~b}$ & 16.64 & \pm & 0.14 & aa \\
\hline & 33 & 62.80 & \pm & 0.57 & f-h & 67.03 & \pm & 0.71 & $c-g$ & 74.45 & \pm & 0.92 & b & 19.64 & \pm & 1.75 & b-d \\
\hline & 55 & 62.65 & \pm & 0.47 & $\mathrm{~d}-\mathrm{g}$ & 66.95 & \pm & 1.06 & $b-g$ & 73.88 & \pm & 1.43 & $\mathrm{~b}$ & 19.06 & \pm & 0.38 & bc \\
\hline \multirow[t]{5}{*}{$\mathrm{AM}$} & 5.5 & 62.00 & \pm & 0.36 & $\mathrm{a}-\mathrm{c}$ & 66.45 & \pm & 0.12 & $\mathrm{a}-\mathrm{c}$ & 73.93 & \pm & 0.04 & a & 20.77 & \pm & 0.18 & $c-\mathrm{e}$ \\
\hline & 11 & 61.86 & \pm & 0.50 & a & 66.28 & \pm & 0.35 & $\mathrm{a}$ & 73.81 & \pm & 0.62 & a & 23.37 & \pm & 1.13 & f \\
\hline & 16.5 & 61.93 & \pm & 0.20 & a & 66.37 & \pm & 0.00 & $\mathrm{ab}$ & 73.86 & \pm & 0.06 & a & 19.43 & \pm & 0.49 & b-d \\
\hline & 33 & 62.24 & \pm & 0.22 & a-e & 66.70 & \pm & 0.24 & $\mathrm{a}-\mathrm{e}$ & 73.12 & \pm & 0.40 & a & 19.82 & \pm & 2.70 & b-e \\
\hline & 55 & 61.98 & \pm & 0.11 & $\mathrm{ab}$ & 66.37 & \pm & 0.24 & $\mathrm{ab}$ & 73.62 & \pm & 0.13 & a & 21.67 & \pm & 0.94 & $\mathrm{~d}-\mathrm{f}$ \\
\hline \multirow[t]{5}{*}{ CGTase } & 0.1 & 62.49 & \pm & 0.12 & $\mathrm{c}-\mathrm{g}$ & 67.28 & \pm & 0.12 & $e-g$ & 73.98 & \pm & 0.12 & $\mathrm{ab}$ & 19.35 & \pm & 1.39 & bc \\
\hline & 0.2 & 61.99 & \pm & 0.01 & $\mathrm{a}-\mathrm{c}$ & 66.37 & \pm & 0.24 & $\mathrm{ab}$ & 73.27 & \pm & 0.46 & ab & 20.99 & \pm & 0.87 & $c-\mathrm{e}$ \\
\hline & 0.3 & 62.01 & \pm & 0.12 & $a-c$ & 66.37 & \pm & 0.00 & $\mathrm{ab}$ & 73.34 & \pm & 0.18 & $\mathrm{ab}$ & 18.15 & \pm & 0.56 & ab \\
\hline & 0.6 & 62.20 & \pm & 0.08 & a-d & 66.62 & \pm & 0.12 & $\mathrm{a}-\mathrm{d}$ & 73.68 & \pm & 0.09 & $\mathrm{ab}$ & 19.47 & \pm & 1.02 & b-d \\
\hline & 1 & 62.46 & \pm & 0.10 & b-g & 67.03 & \pm & 0.24 & $c-g$ & 73.67 & \pm & 0.26 & $\mathrm{ab}$ & 19.11 & \pm & 0.58 & bc \\
\hline \multirow[t]{5}{*}{$\mathrm{BE}$} & 500 & 62.81 & \pm & 0.28 & $\mathrm{f}-\mathrm{h}$ & 67.28 & \pm & 0.12 & e-g & 74.25 & \pm & 0.46 & ab & 23.72 & \pm & 1.00 & $\mathrm{f}$ \\
\hline & 1000 & 62.73 & \pm & 0.40 & e-g & 67.03 & \pm & 0.24 & $c-g$ & 74.18 & \pm & 0.96 & $\mathrm{ab}$ & 21.95 & \pm & 1.43 & ef \\
\hline & 1500 & 62.30 & \pm & 0.05 & $a-f$ & 66.78 & \pm & 0.12 & $a-f$ & 73.30 & \pm & 0.24 & ab & 20.31 & \pm & 0.84 & b-e \\
\hline & 3000 & 62.48 & \pm & 0.28 & b-g & 67.12 & \pm & 0.35 & $d-g$ & 74.04 & \pm & 0.77 & $\mathrm{ab}$ & 20.94 & \pm & 1.39 & $c-\mathrm{e}$ \\
\hline & 5000 & 62.47 & \pm & 0.32 & b-g & 66.87 & \pm & 0.24 & $a-f$ & 73.76 & \pm & 0.19 & ab & 20.02 & \pm & 0.70 & b-e \\
\hline \multirow[t]{2}{*}{ P-value } & Enzyme type & \multicolumn{4}{|c|}{0.00} & \multicolumn{4}{|c|}{0.01} & \multicolumn{4}{|c|}{0.04} & \multicolumn{4}{|c|}{0.03} \\
\hline & Enzyme (U/g) & \multicolumn{4}{|c|}{0.00} & \multicolumn{4}{|c|}{0.00} & \multicolumn{4}{|c|}{0.06} & \multicolumn{4}{|c|}{$\mathbf{0 . 0 3}$} \\
\hline
\end{tabular}


To $=$ onset temperature, $\mathrm{Tp}=$ peak temperature, $\mathrm{Tc}=$ conclusion temperature, $\Delta \mathrm{H}=$ enthalpy change. Values followed by different letters within a column 372 denote significantly different levels $(P<0.05)(\mathrm{n}=3)$. 
374 Porous starches could be obtained by enzymatic treatment of corn starch at sub-

375 gelatinization temperature. The size distribution of the pores and their area were

376 dependent on the type of enzyme used for the starch treatment, but also the level of

377 enzyme. AMG led to porous starches with larger holes, whereas the smallest were

378 obtained with CGTase. Porous starches differed in their pasting performance and

379 thermal properties, besides adsorptive water or oil capacities. By selecting the type of

380 enzyme and its level it could be modulated the degree of porosity.

381 Enzymatic treatment of native starch granules reveals as a powerful tool to modify the

382 properties of starch. The added value and feasibility of this methodology on different

383 sources of starch should be examined.

\section{Acknowledgements}

385 Authors acknowledge the financial support of the Spanish Ministry of Economy and

386 Competitiveness (Project AGL2014-52928-C2-1-R) and the European Regional

387 Development Fund (FEDER). Y. Benavent-Gil would like to thank predoctoral

388 fellowship from Spanish Ministry of Economy and Competitiveness.

\section{References}

390 Aggarwal, P., \& Dollimore, D. (2000). Degradation of starchy food material by thermal 391 analysis. Thermochimica Acta, 357-358, 57-63.

392 American Association of Cereal Chemists, A. (2000). Approved methods of AACC 393 (10th ed.). St. Paul, MN: American Association of Cereal Chemists. Method 76-31.

394 Belingheri, C., Giussani, B., Rodriguez-Estrada, M. T., Ferrillo, A., \& Vittadini, E.

395 (2015). Oxidative stability of high-oleic sunflower oil in a porous starch carrier. Food 396 Chemistry, 166, 346-351.

397 Blackwood, A. D., \& Bucke, C. (2000). Addition of polar organic solvents can improve 398 the product selectivity of cyclodextrin glycosyltransferase: Solvent effects on cgtase. 399 Enzyme and Microbial Technology, 27(9), 704-708.

400 Bouchet-Spinelli, A., Coche-Guérente, L., Armand, S., Lenouvel, F., Labbé, P., \& Fort, 401 S. (2013). Functional characterization of starch-degrading enzymes using quartz crystal 402 microbalance with dissipation monitoring (QCM-D). Sensors and Actuators B: 403 Chemical, 176, 1038-1043.

404 Copeland, L., Blazek, J., Salman, H., \& Tang, M. C. (2009). Form and functionality of 405 starch. Food Hydrocolloids, 23(6), 1527-1534. 
406 Chen, G., \& Zhang, B. (2012). Hydrolysis of granular corn starch with controlled pore 407 size. Journal of Cereal Science, 56(2), 316-320.

408 Chung, H.-J., Liu, Q., \& Hoover, R. (2009). Impact of annealing and heat-moisture 409 treatment on rapidly digestible, slowly digestible and resistant starch levels in native 410 and gelatinized corn, pea and lentil starches. Carbohydrate Polymers, 75(3), 436-447.

411 Dura, A., Błaszczak, W., \& Rosell, C. M. (2014). Functionality of porous starch 412 obtained by amylase or amyloglucosidase treatments. Carbohydrate Polymers, 101, $413 \quad 837-845$.

414 Dura, A., \& Rosell, C. M. (2016). Physico-chemical properties of corn starch modified 415 with cyclodextrin glycosyltransferase. International Journal of Biological 416 Macromolecules, 87, 466-472.

417 Gibson, T. S., Solah, V. A., \& McCleary, B. V. (1997). A Procedure to Measure 418 Amylose in Cereal Starches and Flours with Concanavalin A. Journal of Cereal 419 Science, 25(2), 111-119.

420 Gujral, H. S., \& Rosell, C. M. (2004). Modification of pasting properties of wheat 421 starch by cyclodextrin glycosyltransferase. Journal of the Science of Food and 422 Agriculture, 84(13), 1685-1690.

423 Ichihara, T., Fukuda, J., Takaha, T., Yuguchi, Y., \& Kitamura, S. (2013). Limited 424 Hydrolysis of Insoluble Cassava Starch Granules Results in Enhanced Gelling 425 Properties. Journal of Applied Glycoscience, 61(1), 15-20.

426 Jane, J., Chen, Y., Lee, L., McPherson, A., Wong, K., Radosavljevic, M., \& 427 Kasemsuwan, T. (1999). Effects of amylopectin branch chain length and amylose 428 content on the gelatinization and pasting properties of starch 1. Cereal chemistry, 76(5), 429 629-637.

430 Luo, Z., Cheng, W., Chen, H., Fu, X., Peng, X., Luo, F., \& Nie, L. (2013). Preparation 431 and properties of enzyme-modified cassava starch-zinc complexes. Journal of 432 agricultural and food chemistry, 61(19), 4631-4638.

433 Majzoobi, M., Hedayati, S., \& Farahnaky, A. (2015). Functional properties of 434 microporous wheat starch produced by $\alpha$-amylase and sonication. Food Bioscience, 11, 435 79-84.

436 Ratnayake, W. S., \& Jackson, D. S. (2008). Chapter 5 Starch Gelatinization. Advances 437 in Food and Nutrition Research (Vol. Volume 55, pp. 221-268): Academic Press.

438 Rocha, T. d. S., Carneiro, A. P. d. A., \& Franco, C. M. L. (2010). Effect of enzymatic 439 hydrolysis on some physicochemical properties of root and tuber granular starches.

$440 \quad$ Food Science and Technology (Campinas), 30(2), 544-551.

441 Roussel, X., Lancelon-Pin, C., Viksø-Nielsen, A., Rolland-Sabaté, A., Grimaud, F., 442 Potocki-Véronèse, G., Buléon, A., Putaux, J.-L., \& D'Hulst, C. (2013). Characterization 443 of substrate and product specificity of the purified recombinant glycogen branching 444 enzyme of Rhodothermus obamensis. Biochimica et Biophysica Acta (BBA) - General 445 Subjects, 1830(1), 2167-2177.

446 Sorndech, W., Sagnelli, D., Meier, S., Jansson, A. M., Lee, B.-H., Hamaker, B. R., 447 Rolland-Sabaté, A., Hebelstrup, K. H., Tongta, S., \& Blennow, A. (2016). Structure of 448 branching enzyme- and amylomaltase modified starch produced from well-defined 449 amylose to amylopectin substrates. Carbohydrate Polymers, 152, 51-61.

450 Stevenson, D. G., Doorenbos, R. K., Jane, J. 1., \& Inglett, G. E. (2006). Structures and 451 functional properties of starch from seeds of three soybean (Glycine max (L.) Merr.) 452 varieties. Starch Stärke, 58(10), 509-519.

Sujka, M., \& Jamroz, J. (2007). Starch granule porosity and its changes by means of amylolysis. International agrophysics, 21(1), 107. 
Sun, H., Zhao, P., Ge, X., Xia, Y., Hao, Z., Liu, J., \& Peng, M. (2010). Recent advances 456 in microbial raw starch degrading enzymes. Applied biochemistry and biotechnology, 457 160(4), 988-1003.

458 Terada, Y., Yanase, M., Takata, H., Takaha, T., \& Okada, S. (1997). Cyclodextrins Are 459 Not the Major Cyclic $\alpha-1,4-$ Glucans Produced by the Initial Action of Cyclodextrin 460 Glucanotransferase on Amylose. Journal of Biological Chemistry, 272(25), 1572946115733.

462 Tester, R. F., Qi, X., \& Karkalas, J. (2006). Hydrolysis of native starches with amylases. 463 Animal Feed Science and Technology, 130(1-2), 39-54.

464 Uthumporn, U., Zaidul, I. S. M., \& Karim, A. A. (2010). Hydrolysis of granular starch 465 at sub-gelatinization temperature using a mixture of amylolytic enzymes. Food and 466 Bioproducts Processing, 88(1), 47-54.

467 van der Maarel, M. J. E. C., \& Leemhuis, H. (2013). Starch modification with microbial 468 alpha-glucanotransferase enzymes. Carbohydrate Polymers, 93(1), 116-121.

469 Yamamoto, K., Zhang, Z. Z., \& Kobayashi, S. (2000). Cycloamylose (cyclodextrin) 470 glucanotransferase degrades intact granules of potato raw starch. Journal of agricultural 471 and food chemistry, 48(3), 962-966.

472 Yousif, E. I., Gadallah, M. G. E., \& Sorour, A. M. (2012). Physico-chemical and 473 rheological properties of modified corn starches and its effect on noodle quality. Annals 474 of Agricultural Sciences, 57(1), 19-27.

475 Zhang, B., Cui, D., Liu, M., Gong, H., Huang, Y., \& Han, F. (2012). Corn porous 476 starch: Preparation, characterization and adsorption property. International Journal of 477 Biological Macromolecules, 50(1), 250-256. 